\title{
Characteristics of pulmonary mucormycosis and the experiences of surgical resection
}

\author{
Weipeng Shao ${ }^{1}$, Jun Zhang ${ }^{1}$, Shanwu Ma ${ }^{1}$, Hongxiang Feng ${ }^{2}$, Zhenrong Zhang ${ }^{2}$, Chaoyang Liang ${ }^{2}$, \\ Deruo Liu ${ }^{1}$
}

${ }^{1}$ Department of General Thoracic Surgery, Peking University China-Japan Friendship School of Clinical Medicine and China-Japan Friendship Hospital, Beijing 100029, China; ${ }^{2}$ Department of General Thoracic Surgery, China-Japan Friendship Hospital, Beijing 100029, China

Contributions: (I) Conception and design: W Shao, Z Zhang, D Liu; (II) Administrative support: D Liu; (III) Provision of study materials or patients: All authors; (IV) Collection and assembly of data: W Shao, Z Zhang; (V) Data analysis and interpretation: W Shao, Z Zhang, H Feng; (VI) Manuscript writing: All authors; (VII) Final approval of manuscript: All authors.

Correspondence to: Deruo Liu. Department of General Thoracic Surgery, Peking University China-Japan Friendship School of Clinical Medicine and China-Japan Friendship Hospital, No. 2, Yinghua, East Rd., Beijing 100029, China. Email: deruoliu@163.com.

\begin{abstract}
Background: Pulmonary mucormycosis (PM) is a relatively rare but fatal infection. However, detailed surgery data have been lacking. We summarized the characteristics of this rare disease and clarified the experiences of surgical resection
\end{abstract}

Methods: We conducted a single-center retrospective study of seven patients with PM who underwent surgical resection at China-Japan Friendship Hospital from May 2011 to May 2018.

Results: Patient ages ranged from 18 to 70 years, with a median age of 47 years. Manual workers (85.7\%) were the most common occupation and their educational level was also below high school. Diabetes was the most common underlying condition. The most common radiographic finding was lobar consolidation. Three patients directly underwent open thoracotomy, one patient underwent video-assisted thoracic surgery (VATS) and three patients converted from VATS to thoracotomy. The median operation time was 240 min [interquartile range (IQR), 150-390 min], the median intraoperative blood loss was $500 \mathrm{~mL}$ (IQR, 100$1,200 \mathrm{~mL}$ ) and the median intraoperative blood transfusion was $600 \mathrm{~mL}$ (IQR, 0-1,600 mL). In-hospital, 90-day, 1-year and 5-year mortality were $14.3 \%, 14.3 \%, 28.8 \%$ and $42.9 \%$, respectively.

Conclusions: PM is a rare but fatal infection. Due to chest adhesion and vascular invasion, the proportion of massive bleeding and long operation time has increased sharply.

Keywords: Pulmonary mucormycosis (PM); surgery; operation time; blood loss

Submitted Aug 20, 2019. Accepted for publication Dec 10, 2019.

doi: $10.21037 /$ jtd.2019.12.117

View this article at: http://dx.doi.org/10.21037/jtd.2019.12.117

\section{Introduction}

Pulmonary mucormycosis (PM), formerly known as zygomycosis, is a relatively rare but fatal infection that occurs mostly in immunocompromised persons (1). Diabetes, malignancy and solid organ transplantation were the most common underlying condition (2). PM is an infection caused by the inhalation of spores causing pneumonia with subsequent necrosis and infarction of lung tissue (3). It can also spread directly or hematogenously to surrounding structures in the mediastinum such as the heart or other organs (4).

Although there has been an improvement in the management and outcome of PM over the past few decades, the mortality rate remains high. Mortality varied with the site of infection: $96 \%$ of patients with the disseminated disease died and $76 \%$ with pulmonary infection died $(2,5)$. Management of PM is notoriously challenging due to the lack of evidence-based data to help guide this complicated decision-making process. Treatment consists of antifungal 
drugs, usually amphotericin $B$, and surgical resection of the fungal mass. Previous studies have shown that amphotericin $\mathrm{B}$ is the cornerstone treatment for PM $(6,7)$. Based on the treatment outcomes in patients who received surgical treatment, surgical resection remains be in a dilemma for PM (8). Patients treated with a combined medical-surgical approach had a better outcome than patients who did not undergo surgery $(2,8,9)$.

Because this infection is relatively rare, most reports to date have consisted of either small series or isolated case reports. The purpose of the present study was to analyze the cases of PM from our institution. The specific goals of the study were to characterize the clinical presentation of these patients, to clarify the way of operation, and to compare the effects of medical and surgical treatment for this highly lethal disease.

\section{Methods}

\section{Study population}

This study included patients with PM diagnosed at ChinaJapan Friendship Hospital from May 2011 to May 2018. All patients had the diagnosis established by histologic identification in tissue. Tissue specimens were obtained from a bronchoscopic biopsy. Diagnosis of PM requires histopathological demonstration of characteristic features of fungus showing tissue invasion by aseptate, broad ribbonshaped, right-angled branching hyphae $(10,11)$. This study identified a total of seven patients with PM who received amphotericin $\mathrm{B}$ followed by surgical resection. The patients had undergone surgery after providing informed consent, and the need for individual consent of patients whose records were evaluated was waived because they were not identified in the study. The study was approved by institutional ethics board of China-Japan Friendship Hospital (No. 2018-13-K08). Information about patient data was collected.

\section{Therapeutic measures}

During the study period, the general treatment strategies for PM in our institution were as follows. PM was managed by a multidisciplinary team composed of pulmonologists, intensivists, infectious disease specialists, and thoracic surgeons. As early treatment initiation in patients with invasive fungal diseases, especially $\mathrm{PM}$, has a profound impact on mortality rates, empirical treatment is gaining popularity. An intravenous antifungal agent was initiated immediately after the diagnosis or suspect of PM. amphotericin B was generally recommended as firstline treatment. According to the practice guidelines for the diagnosis and management of aspergillosis, the doses of amphotericin B was recommended range from 0.1 to $1.5 \mathrm{mg} / \mathrm{kg}$ daily (11). In the meantime, according to general criteria for global responses to antifungal therapy, the response to medical therapy was defined as complete, partial, stable response, and failure (12). If the patient's response did not reach complete or partial level, we would recommend surgical treatment.

\section{Statistical analyses}

Given the small sample size and the usually non-normal distribution of covariates, nonparametric tests were utilized in exploratory analyses of the clinical characteristics of these patients. Data are presented as the median and interquartile range (IQR) for continuous variables and as frequency and percentage for categorical variables.

\section{Results}

\section{Demographics}

Between May 2011 to May 2018, a total of seven patients with a PM were registered. Baseline characteristics are summarized in Tables 1,2. Patient ages ranged from 18 to 70 years, with a median age of 47 years. The median body mass index (BMI) was $20.0 \mathrm{~kg} / \mathrm{m}^{2}$ (IQR, 18.6-25.3 kg/m²). A total of $57.1 \%$ of all PM infections occurred in males. Manual workers $(85.7 \%)$ were the most common occupation and their educational level was also below high school. Among all seven patients, four patients had a smoking history and that median smoking-index was 40 (IQR, 0-280).

\section{Underlying conditions}

We found that diabetes was the most common underlying condition from Table 2. Only one patient (14.3\%) with diabetes had type I diabetes. Four (57.1\%) patients with diabetes in this study had type II diabetes. There were $3(42.9 \%)$ cases of PM reported in patients with hypoproteinemia. Of seven patients with PM, 1 (14.3\%) was pulmonary tuberculosis, 1 (14.3\%) was bronchiectasis, $1(14.3 \%)$ was nephrotic syndrome and $1(14.3 \%)$ was 


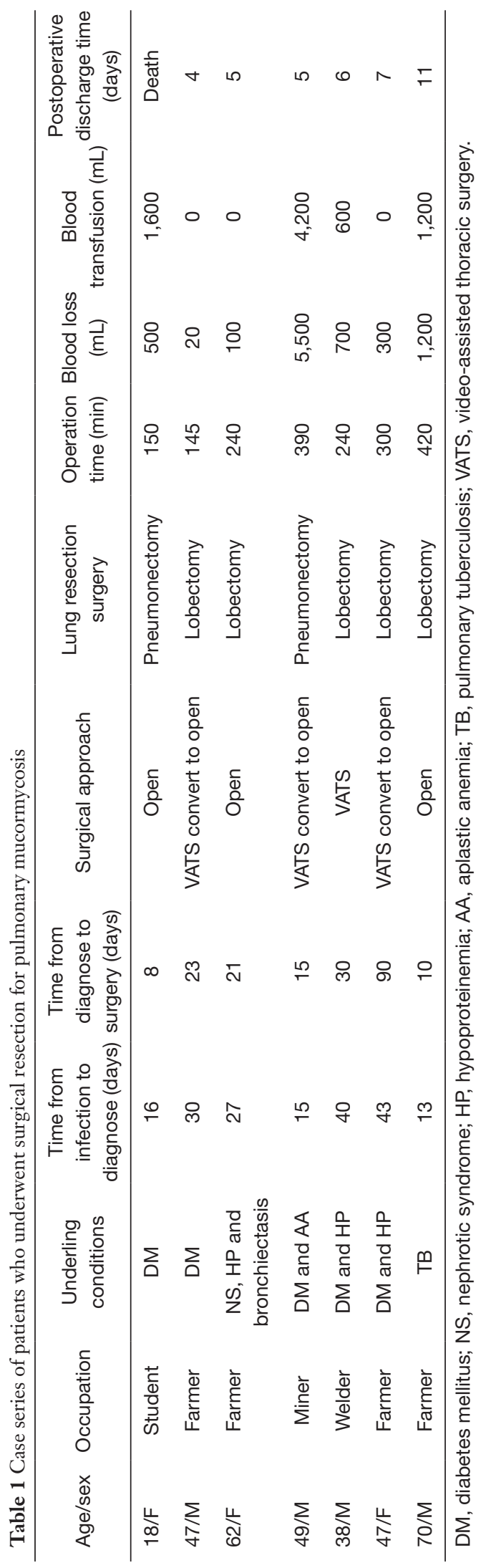

Table 2 Clinical characteristics of patients with pulmonary mucormycosis

\begin{tabular}{lc}
\hline Characteristics & Results \\
\hline Age (years), median [IQR] & 47 [38-62] \\
Male sex, n (\%) & $4(57.1)$ \\
BMI $\left(\mathrm{kg} / \mathrm{m}^{2}\right)$, median (IQR) & $20.0(18.6-25.3)$ \\
Manual worker, n (\%) & $6(85.7)$ \\
Smoking history, $\mathrm{n}(\%)$ & $4(57.1)$ \\
Underlying conditions, $\mathrm{n}(\%)$ & \\
Diabetes & $5(71.4)$ \\
Hypoproteinemia & $3(42.9)$ \\
Pulmonary tuberculosis & $1(14.3)$ \\
Bronchiectasis & $1(14.3)$ \\
Nephrotic syndrome & $1(14.3)$ \\
Aplastic anemia & $1(14.3)$ \\
\hline IQR, interquartile range; BMl, body mass index.
\end{tabular}

aplastic anemia. Four (57.1\%) patients had two or more underlying conditions.

\section{Clinical features}

The clinical features were summarized in Table 3. Fever $(71.4 \%, \mathrm{n}=5)$ was the most common clinical manifestation, followed by expectoration $(42.9 \%, n=3)$, hemoptysis $(42.9 \%$, $\mathrm{n}=3)$ and cough $(14.3 \%, \mathrm{n}=1)$. In seven patients for whom the interval from onset to admission was described, all patients had an acute onset which was defined by symptoms presenting for 30 days or less before admission.

\section{Computed tomographic presentation}

All patients received chest CT scans. The details were described from Table 3. Four patients presented with more than one lobe involved. Upper lobe $(n=4,57.1 \%)$ was more commonly implicated than lower lobe $(\mathrm{n}=3,42.9 \%)$, right lung $(\mathrm{n}=4,57.1 \%)$ was more commonly implicated than left lung ( $\mathrm{n}=3,42.9 \%)$. Lesions were more likely to have central lung involvement and lead to obstructive atelectasis. Considering the effect of pulmonary consolidation, it is difficult to accurately measure the size of the mass. The thick-walled cavity was described on chest CT in four patients. Pleural effusion was reported in three patients (42.9\%). 
Table 3 Clinical features, computed tomographic presentation and diagnosis modalities of patients with pulmonary mucormycosis

\begin{tabular}{|c|c|}
\hline Characteristics & Results \\
\hline \multicolumn{2}{|l|}{ Clinical features, n (\%) } \\
\hline Fever & $5(71.4)$ \\
\hline Expectoration & $3(42.9)$ \\
\hline Hemoptysis & $3(42.9)$ \\
\hline Cough & $1(14.3)$ \\
\hline \multicolumn{2}{|l|}{ CT presentation, n (\%) } \\
\hline \multicolumn{2}{|l|}{ Location } \\
\hline Central & $7(100.0)$ \\
\hline Peripheral & 0 \\
\hline Left lung & $3(42.9)$ \\
\hline Right lung & $4(57.1)$ \\
\hline \multicolumn{2}{|l|}{ Lobe(s) involved } \\
\hline Upper lobe & $4(57.1)$ \\
\hline Middle lobe & 0 \\
\hline Lower lobe & $3(42.9)$ \\
\hline Thick-walled cavity & $4(57.1)$ \\
\hline Pleural effusion & $3(42.9)$ \\
\hline \multicolumn{2}{|l|}{ Diagnosed modalities, n (\%) } \\
\hline Transbronchial biopsy & $5(71.4)$ \\
\hline Bronchoalveolar lavage & $2(28.6)$ \\
\hline
\end{tabular}

\section{Perioperative management}

All patients underwent surgical resection after diagnosed $\mathrm{PM}$. The average time given for medical therapy before progressing to surgical intervention was 20 days (IQR, 30-40 days). The details were described from Tables 4,5. The median time from diagnosis to resection was 21 days (IQR, 10-30 days). There were three patients directly underwent open thoracotomy, one patient completed under video-assisted thoracic surgery (VATS) and three patients converted from VATS to thoracotomy. Of these patients undergoing surgery, lobectomy was performed in five patients, pneumonectomy in two patients. The median operation time was $240 \mathrm{~min}(\mathrm{IQR}, 150-390 \mathrm{~min}$ ), the median intraoperative blood loss was $500 \mathrm{~mL}$ (range, 100$1,200 \mathrm{~mL}$ ) and the median intraoperative blood transfusion was $600 \mathrm{~mL}$ (range, 0-1,600 mL). Vascular invasion, tissue necrosis, and severe adhesion are common during
Table 4 Perioperative period in patients with pulmonary mucormycosis

\begin{tabular}{|c|c|}
\hline Characteristics & Results \\
\hline \multicolumn{2}{|l|}{ ASA classification, $\mathrm{n}(\%)$} \\
\hline 1 & $3(42.9)$ \\
\hline II & $3(42.9)$ \\
\hline III & $1(14.3)$ \\
\hline $\begin{array}{l}\text { Time from diagnosis to resection (days), } \\
\text { median }[I Q R]\end{array}$ & $21[10-30]$ \\
\hline $\begin{array}{l}\text { Medical therapy before progressing to } \\
\text { surgical intervention (days), median [IQR] }\end{array}$ & $20[30-40]$ \\
\hline \multicolumn{2}{|l|}{ Surgical approach, n (\%) } \\
\hline Open & $3(42.9)$ \\
\hline VATS & $1(14.3)$ \\
\hline VATS converted to open & $3(42.9)$ \\
\hline \multicolumn{2}{|l|}{ Lung resection surgery, $\mathrm{n}(\%)$} \\
\hline Lobectomy & $3(42.8)$ \\
\hline Bilobectomy & $2(28.6)$ \\
\hline Pneumonectomy & $2(28.6)$ \\
\hline Operation time (min), median [IQR] & $240[150-390]$ \\
\hline Intraoperative blood loss ( $\mathrm{mL})$, median [IQR] & $500[100-1,200]$ \\
\hline $\begin{array}{l}\text { Intraoperative blood transfusion }(\mathrm{mL}) \text {, } \\
\text { median [IQR] }\end{array}$ & $600[0-1,600]$ \\
\hline \multicolumn{2}{|l|}{ Number of chest tube(s), n (\%) } \\
\hline One & $6(85.7)$ \\
\hline Two & $1(14.3)$ \\
\hline Drainage duration (days), median [IQR] & 4 [3-6] \\
\hline
\end{tabular}

ASA, American Society of Anesthesiologists; IQR, interquartile range.

operation. Adhesion occurred in the chest wall, diaphragm and mediastinum. Pneumonectomy was performed in two cases because of severe hilar adhesion. Two ways to deal with the bronchial stump, three patients received manual suture and four patients underwent mechanical suture. Chest tubes were placed in all seven patients during operation and remained in place a median of 4 days (IQR, 3-6 days) postoperatively. Of the seven patients, 1 had two chest tubes and the other 6 had one tube.

The in-hospital mortality for the entire group was $14.3 \%$. One patient died of an uncontrollable massive thoracic hemorrhage on the first day after the operation. 
Table 5 Intraoperative events and outcomes in patients with pulmonary mucormycosis

\begin{tabular}{ll}
\hline Characteristics & Results \\
\hline Severe thoracic adhesions, $\mathrm{n}(\%)$ & $6(85.7)$ \\
Via intrapericardial management, $\mathrm{n}(\%)$ & $2(28.6)$ \\
Bronchial stump management, $\mathrm{n}(\%)$ & \\
Manual suture & $3(42.9)$ \\
Bronchial stapler & $4(57.1)$ \\
Postoperative complications, $\mathrm{n}(\%)$ & \\
Acute massive hemorrhage & $1(14.3)$ \\
Bronchopleural fistula & $2(28.6)$ \\
Postoperative discharge time (days), & $5[4-7]$ \\
median [IQR] & \\
Mortality, $\mathrm{n}$ (\%) & \\
In-hospital mortality & $1(14.3)$ \\
90-day mortality & $1(14.3)$ \\
1-year mortality & $2(28.6)$ \\
5-year mortality & $3(42.9)$ \\
\hline
\end{tabular}

$I Q R$, interquartile range.

The median discharge time of the seven patients was 5 days (range, 4-7 days) and they did not experience postoperative in-hospital complications. However, two patients developed bronchopleural fistula (BPF) in 2 months and 2 years after discharge, respectively. One patient improved after conservative treatment, another patient underwent bronchoscopic empyema clearance. In-hospital, 90-day, 1 -year and 5-year mortality were 14.3\%, 14.3\%, $28.6 \%$ and $42.9 \%$, respectively. One patient died of new developed lung cancer and the other died of a non-pulmonary disease.

\section{Discussion}

In this study, we showed that seven patients with PM underwent surgical resection. We described the characteristics of PM, and the most important novel finding is that we reported the reasons for the difficulty of the operation and perioperative management.

The incidence of PM was relatively uncommon and difficult to estimate because it was not a reported disease and the risk varies greatly among different populations (9). One population-based study estimated the incidence of mucormycosis to be 1.7 cases per million people per year (13). For the above reasons, we have treated only seven patients in the past 7 years. A study in Germany that found patient ages ranged from 2 to 88 years, with a median age of 49 years in a total of 41 patients with PM (14). In our study, patient ages ranged from 18 to 70 years, with a median age of 47 years. In patients with PM, the maleto-female ratio was higher, reported to be between 2.4:1 and $3: 1(13-15)$. We found that a total of $57.1 \%$ of all PM infections occurred in males. Manual workers $(85.7 \%)$ were the most common occupation and their educational level was also below high school. Male, low education, handicraft workers were susceptible to PM infection. In our country, PM might be more likely to infect people living in harsh environments. Four $(57.1 \%)$ patients had a smoking history. PM was still reported in non-smokers (16), smoking has been demonstrated to be a risk factor in fungal infection (17).

Lanternier et al. and Ruping et al. reported that underlying conditions in France and Germany were reported respectively $(14,18)$, They found that diabetes was a common risk factor. Similarly, we have come to the same conclusion, diabetes was the most common underlying condition. A retrospective study of 929 cases of mucormycosis reported from 1940 to 2003 found that diabetes was the most common risk factor, accounting for $36 \%$ of cases, followed by malignant tumors of the blood system (17\%) and solid organ or hematopoietic stem cell transplantation (12\%) (2). Relevant research showed that in diabetic patients with poorly controlled blood sugar, PM can grow under acidic $\mathrm{pH}$ conditions (19). In 1994, Tedder and his colleagues have found that cough, fever, and pleuritic chest pain were the most common presenting symptoms, but none were specific for PM (15). In our experience, fever was the most common clinical manifestation, followed by expectoration, hemoptysis, and cough. Most patients have not limited to one symptom. Hemoptysis was an important reason for patients wishing to undergo surgery. In a larger data of retrospective analysis, fever and hemoptysis were the important characteristics of PM (2). There are still other complaints, such as shortness of breath $(20,21)$, chest wall tenderness (22), chronic dyspnea (23) and so on.

The most common method used to make the diagnosis of PM in our review was bronchoscopy $(2,9)$.

$\mathrm{PM}$ often demonstrates as infiltration, consolidation, nodules, and effusion on chest CT. Greene et al. believed that the halo sign is an early sign of PM (24). Ruping et al. found that a halo sign was reported in seven patients (31.8\%), an air crescent sign in two patients (9.1\%) (14). Importantly, It was reported recently that the presence of 
the air-crescent sign has been associated with a high risk of massive hemoptysis from centrally located lesions (25). Chamilos and his colleagues reported that the presence of pleural effusion on CT is an independent predictor for poor outcome in PM patients (6). In our research, we found that the most common finding on CT was lobar consolidation. Our results are similar to Feng's research from China (26). They showed that most patients $(95.7 \%)$ with parenchymal involvement all had infiltrated or consolidation on chest CT and reversed halo sign was found only in $9.8 \%$ of patients. We did not find halo sign imaging, which might be explained by the fact that chest CT in our study was not taken immediately after onset, and it was reported that the halo sign would be no longer observed after 2 weeks $(24,27)$.

Many types of researches had recommended antifungal therapy includes AMB deoxycholate administered at the highest tolerated dosage and its effect has been confirmed $(11,28,29)$. However, for deep tissues, the effective concentration of drugs is difficult to achieve (30). Surgical debridement of infected and necrotic tissue is necessary. Many case reports and retrospective analysis supported the need for surgical debridement to optimize outcomes $(2,14,15,22,23)$. Surgical treatment plus antifungal therapy greatly improved outcomes and gradually recognized by most doctors $(8,22,31)$. In our study, only one patient completed under VATS and the other six patients underwent thoracotomy. We found that pulmonary adhered closely to the chest wall, mediastinum and diaphragm during operation. This was one of the reasons for the increased difficulty and prolonged operation time. we put forward three hypotheses about the causes of thoracic adhesions, as follows, one was that the immune function of patients was reduced due to the combination of underlying diseases, leading to the body could not effectively kill or control PM, as a result, pleural inflammation persists. Secondly, because PM was a sub-acute course, patients who delayed admission could not control pleural inflammation in time, pleural effusion might not be discharged in time and exists for a long time. That might increase the incidence of thoracic adhesions. Surgical debridement of infected and necrotic tissue should be performed on an urgent basis. The other reason was the viscera and parietal pleura could produce more fluid into the pleural cavity when pleura inflammation. At the same time, granulation tissue in the pleural wall of PM affects the absorption ability of lymphatic vessel micropore to infective pleural fluid. Another reason for increasing the difficulty and duration of surgery was related to angioinvasion with resultant vessel thrombosis and tissue necrosis $(27,32)$. We also found these changes and it is difficult to distinguish the normal anatomical structure. Thoracic adhesions and angioinvasion greatly increased the difficulty of surgery. Due to severe hilar adhesions and unclear anatomical layers, two patients received a pneumonectomy via intrapericardial management. To ensure no $\mathrm{PM}$ at the bronchial amputation as far as possible, there were two ways to deal with the bronchial stump, three patients received manual suture and four patients underwent bronchial stapler. Tissue necrosis or large size of the mass results in insufficiently broken ends, forcing manual suture. With the above reasons, the operation time was significantly prolonged in our institute. The benefit of pulmonary resection diminishes as dissemination of PM occurs. Lobectomy often is required, aggressive resection, up to and including pneumonectomy, may be warranted to resect all of the diseased lung tissue $(2,29,32,33)$. However, two patients developed a BPF in 2 months and 2 years after discharge, respectively. Closing the fistula and cleaning the abscess cavity were the basic strategies to treat BPF (34).

In-hospital, 90-day, 1-year and 5-year mortality were $14.3 \%, 14.3 \%, 28.6 \%$ and $42.9 \%$, respectively, in our hospital. It was similar to or slightly higher than the rate of previous studies $(30-50 \%)(9,15,29)$. Because of the extensive thrombosis and tissue necrosis, one patient died of an uncontrollable massive thoracic hemorrhage on the first day after the operation. Of the other six patients who underwent surgery, no deaths were attributed to PM. This is valuable information for clinicians attempting to optimize patient selection for surgical resection of PM.

Our study had several limitations. First, it was a retrospective study conducted at a single referral center in China. Second, our study had a small sample size.

\section{Conclusions}

$\mathrm{PM}$ is a rare but fatal infection. Diabetes was the most common underlying condition in our research. Hence the control of blood sugar is particularly important. It was crucial to detect, diagnose, and treat PM at their early stage of onset for improving the cure rate of PM and the survival rate of patients. Our treatment strategies were amphotericin $\mathrm{B}$ and pulmonary resection surgery as soon as possible. But due to chest adhesion and vascular invasion, the proportion of massive bleeding and long operation time has increased sharply. In the meantime, the rate of massive bleeding and long operation time was higher than other diseases, such as lung cancer and benign tumors. Perfect preoperative 
examination, adequate preoperative preparation, rich clinical surgery experience was the key to the successful surgery.

\section{Acknowledgments}

Funding: None.

\section{Footnote}

Conflicts of Interest: DL serves as the unpaid editorial board member of Fournal of Thoracic Disease from Nov 2018 to Oct 2020. The other authors have no conflicts of interest to declare.

Ethical Statement: The authors are accountable for all aspects of the work in ensuring that questions related to the accuracy or integrity of any part of the work are appropriately investigated and resolved. The study was approved by institutional ethics board of China-Japan Friendship Hospital (No. 2018-13-K08). Information about patient data was collected.

Open Access Statement: This is an Open Access article distributed in accordance with the Creative Commons Attribution-NonCommercial-NoDerivs 4.0 International License (CC BY-NC-ND 4.0), which permits the noncommercial replication and distribution of the article with the strict proviso that no changes or edits are made and the original work is properly cited (including links to both the formal publication through the relevant DOI and the license). See: https://creativecommons.org/licenses/by-nc-nd/4.0/.

\section{References}

1. Kauffman CA, Malani AN. Zygomycosis: an emerging fungal infection with new options for management. Curr Infect Dis Rep 2007;9:435-40.

2. Roden MM, Zaoutis TE, Buchanan WL, et al. Epidemiology and outcome of zygomycosis: a review of 929 reported cases. Clin Infect Dis 2005;41:634-53.

3. Helenglass G, Elliott JA, Lucie NP. An unusual presentation of opportunistic mucormycosis. Br Med J (Clin Res Ed) 1981;282:108-9.

4. Afolayan O, Copeland H, Hargrove R, et al. Successful Treatment of Invasive Pulmonary Mucormycosis in an Immunocompromised Patient. Ann Thorac Surg 2016;101:e117-9.
5. Neofytos D, Horn D, Anaissie E, et al. Epidemiology and outcome of invasive fungal infection in adult hematopoietic stem cell transplant recipients: analysis of Multicenter Prospective Antifungal Therapy (PATH) Alliance registry. Clin Infect Dis 2009;48:265-73.

6. Chamilos G, Lewis RE, Kontoyiannis DP. Delaying amphotericin B-based frontline therapy significantly increases mortality among patients with hematologic malignancy who have zygomycosis. Clin Infect Dis 2008;47:503-9.

7. Linden PK. Amphotericin B lipid complex for the treatment of invasive fungal infections. Expert Opin Pharmacother 2003;4:2099-110.

8. Choi H, Lee H, Jeon K, et al. Factors affecting surgical resection and treatment outcomes in patients with pulmonary mucormycosis. J Thorac Dis 2019;11:892-900.

9. Lee FY, Mossad SB, Adal KA. Pulmonary mucormycosis: the last 30 years. Arch Intern Med 1999;159:1301-9.

10. Hamilos G, Samonis G, Kontoyiannis DP. Pulmonary mucormycosis. Semin Respir Crit Care Med 2011;32:693-702.

11. Patterson TF, Thompson GR, Denning DW, et al. Practice Guidelines for the Diagnosis and Management of Aspergillosis: 2016 Update by the Infectious Diseases Society of America. Clin Infect Dis 2016;63:e1-60.

12. Segal BH, Herbrecht R, Stevens DA, et al. Defining responses to therapy and study outcomes in clinical trials of invasive fungal diseases: Mycoses Study Group and European Organization for Research and Treatment of Cancer consensus criteria. Clin Infect Dis 2008;47:674-83.

13. Cohen-Abbo A, Bozeman PM, Patrick CC. Cunninghamella infections: review and report of two cases of Cunninghamella pneumonia in immunocompromised children. Clin Infect Dis 1993;17:173-7.

14. Ruping MJ, Heinz WJ, Kindo AJ, et al. Forty-one recent cases of invasive zygomycosis from a global clinical registry. J Antimicrob Chemother 2010;65:296-302.

15. Tedder M, Spratt JA, Anstadt MP, et al. Pulmonary mucormycosis: results of medical and surgical therapy. Ann Thorac Surg 1994;57:1044-50.

16. Zhang L, Tian X, Wang P, et al. Recurrent pulmonary mucormycosis after lobectomy in a non-smoking patient without predisposing risk factors. Braz J Infect Dis 2012;16:590-3.

17. Baboni FB, Barp D, Izidoro AC, et al. Enhancement of Candida albicans virulence after exposition to cigarette mainstream smoke. Mycopathologia 2009;168:227-35.

18. Lanternier F, Dannaoui E, Morizot G, et al. A global 
analysis of mucormycosis in France: the RetroZygo Study (2005-2007). Clin Infect Dis 2012;54 Suppl 1:S35-43.

19. Ibrahim AS, Spellberg B, Walsh TJ, et al. Pathogenesis of mucormycosis. Clin Infect Dis 2012;54 Suppl 1:S16-22.

20. Fernandez JF, Maselli DJ, Simpson T, et al. Pulmonary mucormycosis: what is the best strategy for therapy? Respir Care 2013;58:e60-3.

21. Al-Sheikhli J, Taqi H, Drake J, et al. Rare cause of pulmonary cavitation in a 75-year-old man. BMJ Case Rep 2018. doi: 10.1136/bcr-2017-222792.

22. Cooke DT, Pagani FD, Kaul DR, et al. Successful treatment of pulmonary zygomycosis in two transplant recipients with liposomal amphotericin B and partial surgical resection followed by posaconazole. Mycoses 2010;53:163-7.

23. Mills SE, Yeldandi AV, Odell DD. Surgical Treatment of Multifocal Pulmonary Mucormycosis. Ann Thorac Surg 2018;106:e93-5.

24. Greene RE, Schlamm HT, Oestmann JW, et al. Imaging findings in acute invasive pulmonary aspergillosis: clinical significance of the halo sign. Clin Infect Dis 2007;44:373-9.

25. Greenberg RN, Scott LJ, Vaughn HH, et al. Zygomycosis (mucormycosis): emerging clinical importance and new treatments. Curr Opin Infect Dis 2004;17:517-25.

26. Feng J, Sun X. Characteristics of pulmonary mucormycosis and predictive risk factors for the outcome. Infection 2018;46:503-12.

27. Spellberg B, Edwards JJ, Ibrahim A. Novel perspectives on mucormycosis: pathophysiology, presentation, and management. Clin Microbiol Rev 2005;18:556-69.

28. Lewis RE, Wiederhold NP. The solubility ceiling: a rationale for continuous infusion amphotericin $\mathrm{B}$ therapy? Clin Infect Dis 2003;37:871-2.

29. Kontoyiannis DP, Lewis RE. Invasive zygomycosis: update on pathogenesis, clinical manifestations, and management. Infect Dis Clin North Am 2006;20:581-607, vi.

30. Ibrahim AS, Spellberg B, Avanessian V, et al. Rhizopus oryzae adheres to, is phagocytosed by, and damages endothelial cells in vitro. Infect Immun 2005;73:778-83.

31. Reid VJ, Solnik DL, Daskalakis T, et al. Management of bronchovascular mucormycosis in a diabetic: a surgical success. Ann Thorac Surg 2004;78:1449-51.

32. Vercillo MS, Liptay MJ, Seder CW. Early pneumonectomy for pulmonary mucormycosis. Ann Thorac Surg 2015;99:e67-8.

33. Maschmeyer G, Haas A, Bohme A. Update on therapy of invasive mycoses in hematology and oncology. Dtsch Med Wochenschr 2005;130:1381-4.

34. Liberman M, Cassivi SD. Bronchial stump dehiscence: update on prevention and management. Semin Thorac Cardiovasc Surg 2007;19:366-73.

Cite this article as: Shao W, Zhang J, Ma S, Feng H, Zhang Z, Liang C, Liu D. Characteristics of pulmonary mucormycosis and the experiences of surgical resection. $\mathrm{J}$ Thorac Dis 2020;12(3):733-740. doi: 10.21037/jtd.2019.12.117 